\title{
Identifying Unwanted Conditions through Chaotic Area Determination in the Context of Indonesia's Economic Resilience at the City Level
}

\author{
Yuyun Hidayat ${ }^{1, *}$, Titi Purwandari ${ }^{1}$, Subiyanto ${ }^{2}$ and Sukono $^{3}$ \\ 1 Department of Statistics, Faculty of Mathematics and Natural Sciences, Universitas Padjadjaran, \\ Sumedang 45363, Indonesia; titipurwandari@yahoo.com \\ 2 Department of Marine Science, Faculty of Fishery and Marine Science, Universitas Padjadjaran, \\ Sumedang 45363, Indonesia; subiyanto@unpad.ac.id \\ 3 Department of Mathematics, Faculty of Mathematics and Natural Sciences, Universitas Padjadjaran, \\ Sumedang 45363, Indonesia; sukono@unpad.ac.id \\ * Correspondence: yuyun.hidayat@unpad.ac.id
}

Citation: Hidayat, Y.; Purwandari, T.; S.; S. Identifying Unwanted Conditions through Chaotic Area Determination in the Context of Indonesia's Economic Resilience at the City Level. Sustainability 2021, 13, 5183. https://doi.org/10.3390/ su13095183

Academic Editor: Anna Visvizi

Received: 19 March 2021

Accepted: 30 April 2021

Published: 6 May 2021

Publisher's Note: MDPI stays neutral with regard to jurisdictional claims in published maps and institutional affiliations.

Copyright: (c) 2021 by the authors. Licensee MDPI, Basel, Switzerland. This article is an open access article distributed under the terms and conditions of the Creative Commons Attribution (CC BY) license (https:// creativecommons.org/licenses/by/ $4.0 /)$.

\begin{abstract}
The purpose of this research is to determine the unwanted condition as a strategic criterion in measuring the economic resilience of a city. A new approach in determining economic resilience was developed to overcome the weaknesses of the index method commonly used internationally. Based on the output of this research, the development priority program for each city becomes distinctive depending on the status of the city's economic resilience. Quality improvement programs are used for cities that do not have resilience and retention programs for cities that already have economic resilience. Five piecewise linear regression parameters are applied to identify a statistical model between Income per capita and $P_{c}$ as a concern variable and modifier variable, and a $Z$. Model is tested massively involving all 514 cities in Indonesia from 2015 to 2019, covering the components of the modifier variable: local revenue (PAD), poverty, unemployment and concern variable ; GRDP and population. The value of the Fraction of variance unexplained (FVU) of the model is $40 \%$. This value is obtained using the Rosenbrock Pattern Search estimation method with a maximum number of iterations of 200 and a convergence criterion of 0.0001 . The FVU area is a condition of uncertainty and unpredictability, so that people will avoid this area. This condition is chaotic and declared as an unwanted condition. The chaotic area is located in the value of $U_{Z}$ less than IDR 5,097,592 and $P_{\mathrm{c}}<P_{\mathrm{c}}\left(U_{\mathrm{Z}}\right)=27,816,310.68$, and thus the coordinates of the chaotic boundary area is $(5,097,592$ : $27,816,310.68)$. FVU as a chaotic area is used as the basis for stating whether or not a city falls into unwanted conditions. A city is claimed not to be economically resilient if the modifier variable $Z$ is in a chaotic boundary.
\end{abstract}

Keywords: unwanted conditions; chaotic area; economic resilience; modifier variable; concern variable; Piecewise regression

\section{Introduction \\ 1.1. The Background of the Study}

Resilience is an "ecological" concept that emphasizes the magnitude of the disturbance that a region is able to absorb before it deviates from the original state. This is the second approach to resilience adopted in this research.

Strengthening economic resilience for quality and equitable growth is included as a National Priority in the Government of Indonesia Work Plan 2021. The plan carries the theme "Accelerating Economic Recovery and Social Reform" [1]. Economic resilience is a strategic issue of the Indonesian State, which is reflected in the statement of the Bank of Indonesia-BI policy synergy, where the government and related authorities are strengthened to maintain economic resilience and encourage economic growth [2]. National 
economic resilience is currently in a fragile state. Strengthening economic resilience is also a key recommendation in the Policy Brief: Strengthening Macroeconomic Resilience \& Competitiveness for the Acceleration of Inclusive \& Quality Economic Growth [3].

Currently, economic resilience in Indonesia is measured using the index approach. The socialization of the National Resilience Index measurement, including the economic resilience index, is continuing. According to the findings, economic resilience is in a pretty strong position [4]. The measurement using the index is not carried out only by Indonesia. The number of Indexes in existence around the world is growing every year [5].

A new approach is needed to assess the level of economic resilience of a city by taking into account the disturbance factor and its impact. The reason for this is that an index number cannot answer the question: "resistant to what?" The economic resilience index only informs that a greater index value indicates that a city is getting more and more resilient. The basic question is: what is a city/region/country resilient to? What disturbances cause a city to fall into an unwanted condition? The index is not enough because it is not able to identify specifically which disturbance factors significantly influence the economic resilience of the city. The index is also unable to identify the intensity level of disturbance at which a city will fall into unwanted conditions, such that it is classified as not resilient economically. Say a city has an economic resilience index of 90 (1-100 scale). What economic shocks is an index of 90 resilient to? An index is necessary but not sufficient to comprehensively explain the economic resilience of a system. An index substantially reflects the average statistics, so it is clear that the index cannot answer the question "resilience to what?" An index does not explain a mathematical model regarding the relationship between two or more variables-in this case, the disturbance variable and the unwanted variable. The model can help us understand how to make the city's economy able to withstand the next shock. This research disagrees with the work of earlier researchers with the approach that determines economic resilience based only on the index. This research also disagrees with the existing theories that determine economic resilience based only on the disturbance model. A city is declared resilient to economic disturbance if it does not fall into unwanted conditions. Based on the critical review of earlier researchers and existing theories, there is not a single paper that explicitly stipulates unwanted conditions as a criterion for determining the economic resilience status of a city. As shown in the literature review of economic resilience, if it is not reflected by an index number, then economic resilience is described in a disturbance model. There is no literature that explicitly defines the unwanted conditions.

\subsection{The Research Problem}

Currently, Indonesia and many researchers in other countries have chosen to use the Index to measure the status of its economic resilience. The National Resilience LabIndonesia stated that "The Covid-19 pandemic has drastically reduced the economic resilience index. The substantial meaning of resilience raises a relevant and fundamental research question, namely "resilience to what?" To disturbances, of course. The strategic research question is the following: "how strong must a city be to withstand the effect of an economic shock, and at what intensity?" The next question is: "what are the criteria for a city's economic resilience in the context of the disturbance?" The index cannot provide an answer to that question, but a model that shows the interrelation between the disturbance variable and the unwanted condition can. The economic resilience of a city requires the existence of unwanted conditions and level of disturbance factors. This research focuses on how to determine the unwanted conditions as one of the two key determinants of cities' economic resilience.

\subsection{The Motivation of the Study}

The approach to measuring economic resilience by simply setting an index, as carried out by many researchers, encourages authors to develop a new approach. A new approach is needed to assess the level of economic resilience of a city that takes into account the 
interrelation between the modifier variable and the concern variable. The motivation of this study is to develop a method to determine the unwanted condition as a strategic criterion in measuring the economic resilience of a city. The results of this research are directed at contributing to the economic development of a country. This new method of determining economic resilience based on unwanted conditions is very important and urgent for the economic development of a country. In an effort to control the stability of a city's economic resilience, a comprehensive and in-depth research is needed on the level of the economic resilience of a city. This is because the condition of a city's economic resilience is dynamic in the context of responding to, and reducing economic disruption to, the concerns of the city's economic development [6].

\section{Literature Review}

\subsection{Economic Resilience}

The study of various literature about economic resilience in this section strongly supports the author's opinion that the measurement of economic resilience must involve disturbance factors. Disturbance factors are then studied for their effects on the economic resilience of a system (city, province, country). The significant effects are studied by their impact on economic resilience status. A system is declared to have no economic resilience if, after experiencing a certain intensity of disturbance, the economic resilience variable is in an unwanted condition and vice versa. Below are some discussions on economic resilience.

There are three ways of assessing the economic resilience of the regions. The first is based on the so-called "engineering" concept of resilience [7]. This approach is easily applicable and is used in the studies of the British economist and geographer Ron Martin [8,9]. The supporters of this approach defined economic resilience as the ability of countries to withstand shocks and to recover quickly [10], and economic resilience as the ability of an area to respond and recover from disturbances [11]. Others define economic resilience as the ability of a region to recover successfully from economic shocks [12]. The same thing is expressed as the ability of an area to recover from disturbances [13], and, within this approach, economic resilience refers to the ability of the local economic system to recover from an elastic shock [14]. Engineering resilience focuses upon forecasting the likelihood of catastrophic events and systemic breakdowns and their social and economic implications [15]. The paper from the World Bank states that Macroeconomic resilience has two components: instantaneous resilience and dynamic resilience, which is the ability to reconstruct and recover. The paper proposes rules of thumb to estimate macroeconomic and microeconomic resilience based on the relevant parameters in the economy [16]. The second approach to resilience is an "ecological" concept that emphasizes the magnitude of the disturbance that the region is able to absorb before it deviates from the original state [17]. The two approaches mentioned above are criticized because they do not sufficiently address the economic development perspective over the long term $[18,19]$. Resilience turns into the continuous ability to adjust to stress [20]. Opinions vary about the definition of resilience, and there is no mainstream approach to the measurement and expression of resilience. Therefore, there are no uniform strategies for strengthening the resilience of economies. This research adopts the second approach.

The measurement of national resilience was carried out by the National Resilience Lab-Indonesia [21], and the results of the measurement of national resilience in the form of a resilience index were scored from 1 to 5 : a score of 1 reflects vulnerability, a score of 2 reflects less resilience, a score of 3 reflects a more considerable resilience, a score of 4 reflects toughness, and a score 5 reflects considerable toughness. Recently, the National Resilience Lab-Indonesia reported that "The Covid-19 pandemic has drastically reduced the economic resilience index, in January 2020, Indonesia's economic resilience reached a score of 3.08 and fell free to reach 2.65 in June 2020" [22].

Bruneckiene et al., (2018) measures the regional resilience to economic shocks. This study is based on six capacity groups consisting of 65 indicators using the Pearson correlation coefficient and the Kendall Rank correlation coefficient, and obtained, from the 
research results, the insight capacity index, the regional government capacity index, the knowledge and innovation capacity index, the learning capacity index and the infrastructure capacity index [23]. Research conducted by Li et al., (2019) analyzed the regional economic resilience of Liaoning province, in China, and explored the determinants of regional economic resilience using a spatial econometric model on panel data. The results of the analysis were that the level of regional economic resilience in Liaoning was low, the urban economy was vulnerable to external shocks, governance regulatory factors and regional innovation capability, and the level of economic diversification has a significant positive effect on regional economic resilience [24]. Research to throw light on some of the underlying aspects of regional resilience and provide an overview of the notion, as well as an analysis of the research studies on constructing the territorial composite indices (CIs), was also carried out by Stanickova and Melecky [25]. The main results of the paper are an overview and a comparison of regional resilience literature and the empirics of existing CIs that lead to measuring the European Union regions' resilience based on constructing their own index. The study reported that CI construction suffers from many methodological difficulties, with the result that they can be misleading and easily manipulated. CI may also be misused, e.g., to support the desired policy, if the construction process is not transparent and/or lacks sound statistical or conceptual principles [25]. The analysis by Di Caro (2017) of a number of US cities hit by shocks concludes that regional differences in economic resilience are explained by the presence of spatial interactions and by adopting a set of determinants like economic diversity, export performance, financial constraints and human and social capital [26]. This paper exploits the properties of the non-linear smooth-transition autoregressive model. The analyses of the economic resilience and its main determinant factors of the regions of seven Eastern European countries by Oprea et al., (2020) concludes that the determining factors of resilience for the studied regions concern the size of the manufacturing sector, the services and public administration, entrepreneurship and the human capital represented by tertiary education; agriculture and urban population have no significant influence on regional resilience [27]. This study adopted an econometric approach using a quantile regression for the analysis. The following descriptions show that the measurement of economic resilience using index numbers is still common practice internationally.

The economic resilience index uses microeconomic, mesoeconomic and macroeconomic variables, and the results of the study obtained the framework for determining an economic resilience index developed by Simmie and Martin (2010) [28]. Research on economic resilience was also carried out by Oliva and Lazzeretti (2018) [29]. This study discusses regional economic resilience in the face of natural disasters by establishing a resistance and recovery index for Japan, which was hit by a major earthquake, while the factors studied were regional demographics, economic aspects, labor and social innovation, using the resistance index and sensitivity index [30] with the following formula:

$$
\begin{gathered}
\text { Resistance index }=\beta_{r e s}=\frac{\left(E_{p, t} / E_{p, t-1}\right)}{\left(E_{w, t} / E_{w, t-1}\right)} \\
\text { Recovery index }=\beta_{r e c}=\frac{\Delta E_{p}}{\Delta E_{p, t}}
\end{gathered}
$$

$E$ represents the total employment, and $\Delta E / E$ is the percentage change in employment. If $\beta$ res is greater than 1 , the region has a low relative resistance to the shock. On the contrary, if $\beta$ res is lower than 1, the region has a high relative resistance to the shock. The recovery is measured as the change in employment in the region in the post-crisis period and shows the ability of the region to grow—or decline—after a shock. Research under the title Theoretical and Empirical Analysis of Economic Resilience Index on economic resilience indexes was applied to developing countries, and the definition of regional economic resilience refers to the ability of the local economic system to recover from an elastic shock [29]. Research to measure the economic resilience index is based on four aspects, namely macroeconomic 
stability, microeconomic market efficiency, governance and social development, using the simple average also developed by Briguglio et al., (2009) [31]. Bakhtiari and Sajjadieh (2018) have conducted research on the economic resilience index applied to developing countries, including Iran, involving dimensions of macroeconomic stability, market efficiency, governance, human development indicators, producing macroeconomic stability index, efficiency market index, government index and human development indicators [14].

Based on a comprehensive literature study, there is no study that determines economic resilience using unwanted conditions specifically.

\subsection{Hypothesis}

In this paper, the variable $Z$, which is the ratio between local revenue (PAD) and the number of poor people in a city, is an economic resilience variable. This variable functions as an absorber or shock breaker when external shock occurs. This variable is also called modifier variable because it is fully controllable by management. The concern variable studied is Income per Capita, $\mathrm{Pc}$, the ratio between gross regional domestic product (PDRB) and Population of the city. $\mathrm{Z}$ functions to reduce economic disturbances so that Pc, the concern variable, remains stable or remains within the set point. This leads to the hypothesis that there is a statistical model that shows a positive relationship between $Z$ and Pc. The study formalizes a test of the hypothesis that $Z$ is a modifier for per capita income by examining whether or not the changes in variable $Z$ affect changes in Pc, Income per capita. If this relationship is proven to be statistically significant, then $Z$, which falls into the unwanted condition, will also be followed by Income per capita.

\section{Methodology}

\subsection{Data Collecting and Data Quality Control}

This economic resilience model was developed limited to economic variables with data published by the Central Bureau of Statistics Indonesia for a period of five years, 2015 to 2019 [32]. Data Collecting is administered by an internet search and web-based data collecting. To reduce errors and avoid garbage in garbage out data, quality control is carried out with the following steps:

Step 1 . Using the $30 \%$ principle.

A control chart is constructed in such a way that $30 \%$ of the data become outliers. An Individual Moving Average Control Chart (I-Chart) is used for this purpose [33], with the following formula:

$$
\text { Center line }=\bar{X}
$$

which corresponds to the process average (the mean of the normal distribution). This line is usually plotted as a horizontal solid line. Above and below this are the upper control limit (UCL) and lower control limit (LCL) lines, which represent L standard deviations above and L standard deviations below the process mean. L is the "distance" of the control limits from the center line, expressed in standard deviation units

$$
\bar{X} \pm \mathrm{L}_{\sigma}
$$

Step 2. Check whether or not all outliers' data are valid. If no errors are found in the data outliers, the data checking process is stopped. Replace wrong data in outliers with new data in the data source and save the web page. This is a standard practice, since electronic data is prone to change due to many reasons. After correcting all errors in the outliers' data, carry out Step 1.

Thus, as long as there are wrong data in the outliers, reconstruct the I-chart using the $30 \%$ principle and recheck the outliers. Using the 30 pct. principle, it will always have outliers. The process must hunt for those outliers until all outliers' data are valid (accepted number of false alarm), but data that have been checked and corrected must not be included in control chart reconstruction and outlier finding. 


\subsection{Data}

Data are collected using $100 \%$ sampling (census) on each of the two elements of the modifier and concern variables. The census is done by web-based data collecting. The two variables are observed and collected from all 514 cities in 34 provinces in Indonesia for a period of 5 years, from 2015 to 2019 (attach as an Annex 1.)

As a preparatory step for data analysis, data quality control has been carried out by the following the steps, in Section 3.1. Given the large number of results obtained, not all of the data quality control results are presented. The following are data quality control processes for PDRB or GRDP data. Thirty percent of the GRDP data are filtered as outliers using the Lower Control Limit (LCL) and the Upper Control Limit (UCL). Then, the data are checked for accuracy by comparing them with the true value. The true value is the GRDP data listed on the Central Bureau of Statistics Web [34]. The Control Limit computations for the data are:

$$
\begin{gathered}
\mathrm{CL}=18,620,136,783,375 \\
\mathrm{LCL}=2,489,482,452,194 \\
\mathrm{UCL}=34,750,791,114,556 \\
\mathrm{~L}=4.451 z
\end{gathered}
$$

and the control chart is presented in Figure 1. In the first iteration, 771 cells of data were checked to ensure their accuracy.

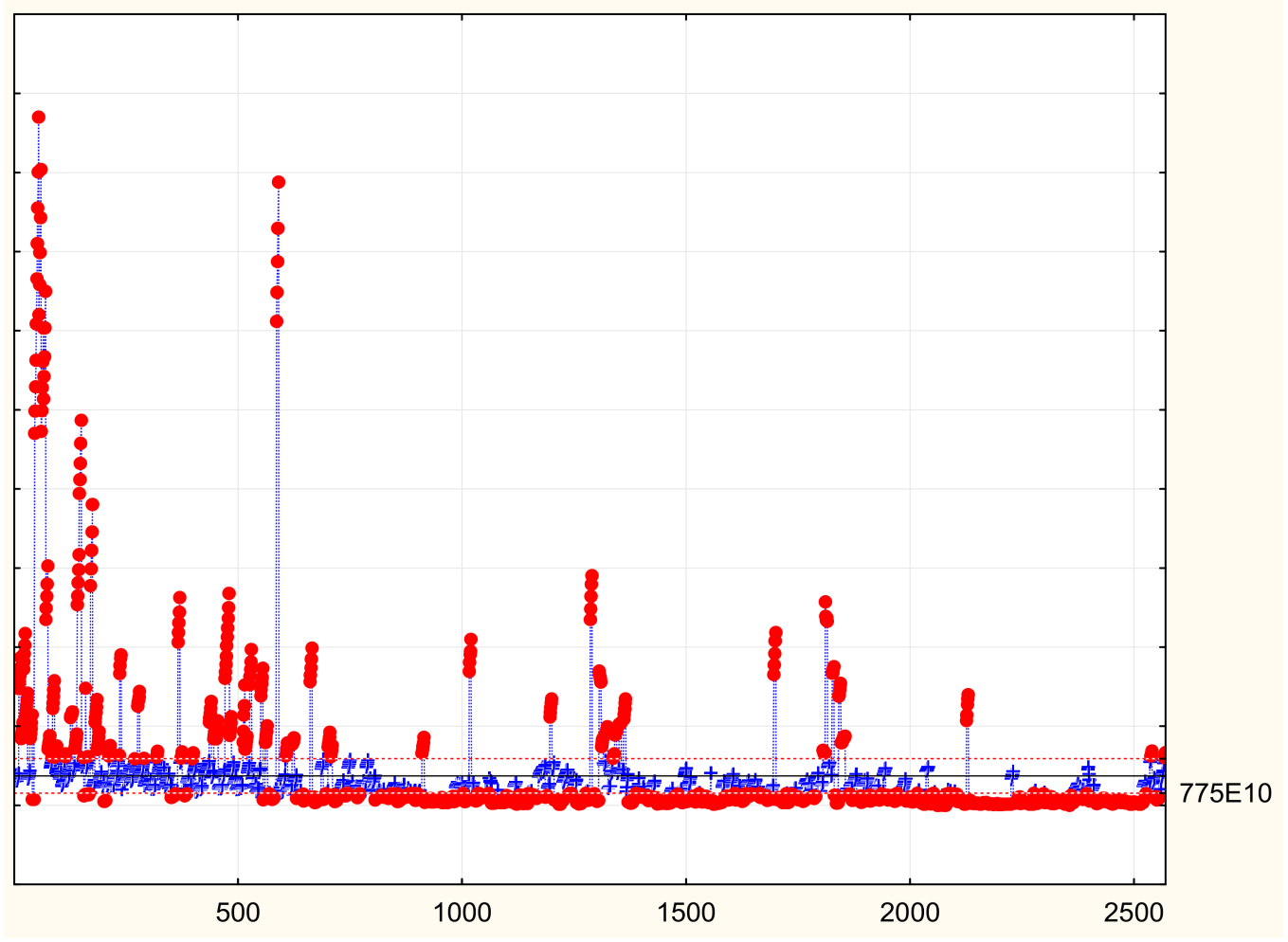

Figure 1. Control Chart for GRDP Data Quality Checks.

\subsection{Methods}

Economic resilience shows the ability of the government to return to the normal-set point level after receiving economic shocks (withstand or recover from the effects of such shocks). This is possible if there exist variables that correlate with the concern variable and can be controlled by the city government. This variable functions as an absorber or shock breaker when external shock occurs. This variable is also called modifier variable, 
$Z$. This research is a quantitative study to examine a statistical model of the relationship between two groups of variables, specifically to analyze the influence of $\mathrm{Z}$ as modifier variable (independent variables) on a Pc as concern variable (dependent variable). In this paper, $\mathrm{Z}$ is defined as the ratio between the original incomes of the region (PAD) and the number of poor people in a city. The concern variable studied is $\mathrm{Pc}$, the ratio between the gross regional domestic product (PDRB) and population for every 514 cities in Indonesia. The relationship between the independent $Z$ variable and the Pc response variable cannot be explained by a simple linear regression model; a single line is not sufficient to model the data set adequately. Piecewise regression is a special type of linear regression that arises when one line is simply not enough. Piecewise linear regression analysis is a form of regression that includes various linear regression models that match the data for each $X$ interval $[35,36]$.

Piecewise regression breaks the domain into potentially many "segments" and fits a separate line through each one. In the graphs in Figure 2, a single line is not able to model the data as well as a piecewise regression with two lines.

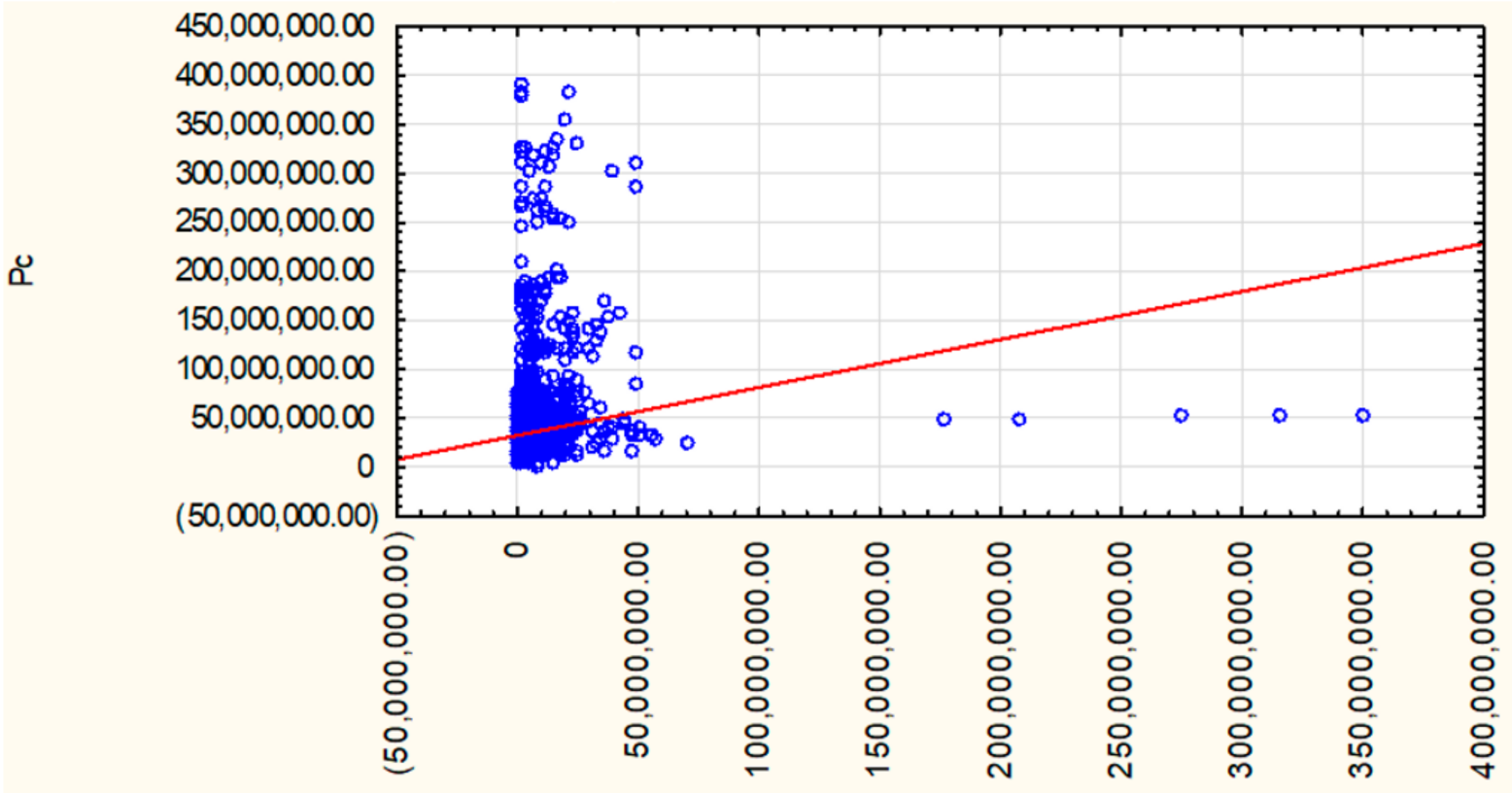

Figure 2. Scatterplot Pc against Z.

Piecewise regression, also known as segmented regression, is a method in regression analysis in which the independent variable is partitioned into intervals and a separate line segment is fit to each interval. Piecewise regression is useful when the independent variables, clustered into different groups, exhibit different relationships between the variables in these regions. The boundaries between the segments are breakpoints. In our use cases, segmented linear regression with two segments separated by a breakpoint was studied. This Segmented linear regression is useful to quantify an abrupt change of the response function $(\mathrm{Pc})$ of a varying influential factor $(\mathrm{Z})$. The breakpoint can be interpreted as a critical, safe or threshold value beyond or below which (un)desired effects occur. The breakpoint can be important in decision making [37].

Segmented regression analysis is based on the presence of a set of $(y, x)$ data, in which $y$ is the dependent variable and $x$ the independent variable. The Rosenbrock Pattern search estimation method is applied simultaneously to each segment, by which the two regression lines are made to fit the data set as closely as possible while minimizing the errors. That is, 
making each segment's regression line close to the observed data points or minimizing the sum of squares of the differences (SSD) between observed $(\mathbf{y})$ and calculated $\left(Y_{r}\right)$ values of the dependent variable, resulting in the following two equations:

$$
\begin{aligned}
& Y_{r}=A_{1} x+K_{1} \text { for } x<B P \text { (breakpoint) } \\
& Y_{r}=A_{2} x+K_{2} \text { for } x>B P \text { (breakpoint) }
\end{aligned}
$$

where:

$Y_{r}$ is the expected (predicted) value of $\mathrm{y}$ for a certain value of $\mathrm{x}$;

$A_{1}$ and $A_{2}$ are regression coefficients (indicating the slope of the line segments);

$K_{1}$ and $K_{2}$ are regression constants (indicating the intercept at the $y$-axis).

In our case, the number of parameters to be estimated using the Rosenbrock Pattern search estimation method is five. The estimation method also produces the combined $\mathrm{R}$ correlation coefficient of the two regression segments as a loss function. The estimation process is run with the STATISTICA software. Thus, STATISTICA estimates two separate linear regression equations; one for the $y$ values that are less than or equal to the breakpoint and one for the $y$ values that are greater than the breakpoint.

$$
\begin{aligned}
& R_{1}^{2}=1-\frac{\sum_{i=1}^{n}\left(y_{i}-Y_{r}\right)^{2}}{\sum_{i=1}^{n}\left(y_{i}-Y_{a 1}\right)^{2}} \text { for } x<B P \text { (breakpoint) } \\
& R_{2}^{2}=1-\frac{\sum_{i=1}^{n}\left(y_{i}-Y_{r}\right)^{2}}{\sum_{i=1}^{n}\left(y_{i}-Y_{a 2}\right)^{2}} \text { for } x>B P \text { (breakpoint) }
\end{aligned}
$$

where:

$\sum_{i=1}^{n}\left(y_{i}-Y_{r}\right)^{2}\left\{\backslash\right.$ displaystyle $\backslash$ sum $\left.\left(\mathrm{y}_{-} Y_{-}\{\mathbf{r}\}\right)^{\wedge}\{2\}\right\}$ is the minimized SSD per segment and $Y_{a 1}$ and $Y_{a 2}$ are the average values of $y$ in the respective segments. The Rosenbrock procedure, which does not require the solution of nonlinear equations, has been investigated in [38-40]. The implementation of this procedure requires only the solution of linear systems of algebraic equations, a much simpler task compared to the first two approaches. The alternative estimation method of the Rosenbrock Pattern search estimation is Hooke-Jeeves Pattern Moves. Convergence is a pattern search method, which proved that it converges using the theory of positive bases proposed by Dodangeh et al., (2016) [41]. In a sense, this is the simplest of all algorithms. The Hooke-Jeeves method comprises an iterative application of an exploratory move in the locality of the current point and a subsequent jump using the pattern move. If the pattern move does not take the solution to a better region, the pattern move is not accepted and the extent of the exploratory search is reduced. The step sizes in this process are constantly adjusted to "zero in" on the respective optimum. Recently, positive-basis techniques to prove the convergence of another pattern-search method on specific classes of functions were developed by researchers [42-44]. Outside of such classes, pattern search is not an iterative method that converges to a solution; indeed, pattern-search methods can converge to non-stationary points on some relatively tame problems [45]. In the Hooke-Jeeves method, a combination of exploratory moves and heuristic pattern moves is made iteratively. An exploratory move is performed systematically in the vicinity of the current point to find the best point around the current point [46]. In the exploratory move, the current point is perturbed in positive and negative directions along each variable, one at a time, and the best point is recorded. If the point found at the end of all variable perturbations is different from the original point, the exploratory move is a success; otherwise, the exploratory move is a failure. In any case, the best point is considered to be the outcome of the exploratory move. Finally, the pattern search method of Hooke and Jeeves [47] consists of a sequence of exploratory moves about a base point which, if successful, are followed by pattern moves. Finally, there is great interest in the literature in discovering unwanted conditions using chaotic systems with closed curves of equilibrium points. 
Chaos theory is a branch of mathematics focusing on the study of chaos-states of dynamical systems in which random states of disorder and irregularities are often governed by deterministic laws that are highly sensitive to initial conditions [30].

Chaotic behavior exists in many natural systems, including fluid flow, heartbeat irregularities, weather and climate [48]. It also occurs spontaneously in some systems with artificial components, such as the stock market and road traffic [49,50]. This research defines the word chaos-according to common usage, "chaos" means "a state of disorder".

There are fractions of variation in dependent variables that cannot be explained by changes in independent variables. In statistics, the coefficient of determination, known as $R^{2}$ and pronounced "R squared", is the proportion of the variance in the dependent variable that is predictable from the independent variable(s). It provides a measure of how well-observed outcomes are replicated by the model, based on the proportion of the total variation of outcomes explained by the model [51-53].

In statistics, the fraction of variance unexplained (FVU) in the context of a regression task is the fraction of variance of the regress and (dependent variable) $Y$ which cannot be explained, i.e., which is not correctly predicted, by the explanatory variables $\mathrm{X}$.

The fraction of variance unexplained (FVU) is defined as:

$$
\mathrm{FVU}=1-R^{2}
$$

FVU area is a condition of irregularities, uncertainty and unpredictability, so that people will avoid this area. This condition is chaotic and declared as an unwanted condition. Thus, FVU represents a measure of the uncertain or unpredictable conditions. That is the reason why, in this study, the chaotic area is determined based on the area corresponding to the FVU. Explicitly, the fraction of variance unexplained area is used as a chaotic area.

The issue of unwanted conditions in economic resilience research is unique, so that in this paper a new method is created to determine the unwanted condition using a chaotic area approach. The research made on the particular case of Indonesia can be generalized using the fraction of variance unexplained (FVU) statistics as a measure of a chaotic area. As long as the FVU can be determined from any statistical model, it is always possible to set uncertainty areas which are unpredictable areas or chaotic areas as unwanted conditions for policymakers in various systems. The method in this research was developed to overcome the shortcomings of the method of measuring economic resilience using the index approach. In the Introduction section, it has been stated that researchers who use the index to measure resilience do not only occur in Indonesia but also internationally.

A chaotic area method is developed, and the procedures are presented in the following steps:

Step 1. Determine the model that best explains the relationship between the variable concern, $P_{c}$, and the modifier variable $Z$. The best model between $Z$ and $P_{c}$ must have a large $Z$ regression coefficient and a small $B_{0}$ intercept, and not the other way around.

Step 2. The determined $P_{\mathrm{c} 1}$ which is the smallest $P_{\mathrm{c}}$ value above the intercept $\left(\mathrm{B}_{0}\right)$. $\mathrm{B}_{0}$ is obtained from the model in Step 1.

Step 3. Determine the chaotic pairs. Filter and separate the origin of data pairs $\left(P_{c}, Z\right)$ and get all pairs of $\left(P_{\mathrm{c}}, Z\right)$ for each $P_{\mathrm{c}}<P_{\mathrm{c} 1}$, and the filter pairs are called a chaotic pair. Equations 8 and 9 are not used to get the $Z$ value because the $\left(P_{c}, Z\right)$ pairs are in the chaotic area, which is in the uncertainty area. No model can explain $P_{\mathrm{c}}$ based on $Z$ in this chaotic area. $Z, U_{\mathrm{Z}}$.

Step 4. Identify the distribution model of $Z$ in chaotic pairs and compute the mean of

Step 5. Find $P_{\mathrm{C}}$ by substituting the $U_{\mathrm{Z}}$ value into the model obtained in Step 1, call it $P_{\mathrm{c}}\left(U_{\mathrm{Z}}\right)$ and then create a chaotic coordinate: $\left(U_{\mathrm{Z}}, P_{\mathrm{c}}\left(U_{\mathrm{Z}}\right)\right)$.

Step 6. Check whether or not $P_{\mathrm{c}}\left(U_{\mathrm{Z}}\right)>P_{\mathrm{c} 1}$. If yes, then stop. The chaotic area is obtained; the output in Step 6 is the chaotic boundary area with $\left(U_{\mathrm{Z}}, P_{\mathrm{c}}\left(U_{\mathrm{Z}}\right)\right)$ coordinates or, in other words, the chaotic boundary is limited by ordinate $P_{\mathrm{c}}\left(U_{\mathrm{Z}}\right)>P_{\mathrm{c}}\left(U_{\mathrm{Z}}\right)$ and abscissa $Z<U_{Z}$. 
Step 7. If $P_{\mathrm{c}}\left(U_{\mathrm{Z}}\right)>P_{\mathrm{c} 1}$, increase $U_{\mathrm{Z}}$ by $k \sigma$ and repeat Step 5 , where $k \sigma$ is the $k$-standard deviation of $Z$. This constraint is to ensure that the $P_{c}$ value obtained is outside the chaotic area, because every $P_{\mathrm{c}}$ value that is obtained under $P_{\mathrm{c} 1}$ is an unreliable value. This is a consequence of the unpredictable nature in the chaotic area of $40 \%$.

\section{Results and Discussion}

A model of the relationship between modifier variables $Z$ and concern variables $P_{\mathrm{c}}$ is obtained using the mechanism as follows: Data for modifier variables and concerns are collected from the website of the Central Bureau of Statistics Indonesia and presented in a 5-year time series (2015-2019) for 514 cities throughout Indonesia. The modifier variable studied is $Z$, the ratio between PAD and the number of poor people in every 514 cities. The concern variable studied is $P_{c}$, the ratio between gross regional domestic product (PDRB) and population for every 514 cities. A total of 2570 observation units on each variable PAD, number of poor people, PDRB and population is collected to analyze the model of the relationship between modifier variables $Z$ and concern variables $P_{c}$. The mean of $P_{c}$ is IDR 35,559,642.42 per year, and the mean of $Z$ is IDR 7,919,249.12. Table 1 shows that the relationship between the independent $Z$ variable and the $P_{\mathrm{C}}$ response variable cannot be explained by a simple linear regression model.

Table 1. ANOVA ${ }^{\mathrm{a}}$ non significance linear relationship between $P_{\mathrm{c}}$ and $\mathrm{Z}$.

\begin{tabular}{cccccc}
\hline Model & Sum of Squares & df & Mean Square & F & Sig. \\
\hline Regression & 11130721131151750.000 & 1 & 11130721131151750.000 & 4.876 & $0.027^{\mathrm{b}}$ \\
\hline Residual & 5862236805334794200.000 & 2568 & 2282802494289250.000 & \\
\hline Total & 5873367526465945600.000 & 2569 & & & \\
\hline
\end{tabular}

- $\quad$ Dependent Variable: Pc

- $\quad$ Predictors: (Constant), Z

The F-test of overall significance indicates that a simple linear regression model does not provide a better fit to the data. Compare the $p$-value of 0.027 for the F-test to 0.01 significance level. The $p$-value is greater than the significance level, and the sample data does not provide sufficient evidence to conclude that the simple linear regression model fits the data better than the model with no independent variables. The R Square of this model is 0.024 , and thus the strength of the relationship between the model and the dependent variable Pc is very weak. The percentage of the response variable variation that is explained by a linear model is only $2.4 \%$, which indicates that a simple linear regression model does not provide an adequate fit to the data. So far, the hypothesis is not proven in simple linear regression models.

The best model that can explain the behavior of $P_{\mathrm{c}}$ as a concern variable by variable modifier $Z$ is to use advanced models that are related to non-linear estimation techniques. Specifically, the piecewise linear regression analysis method has been chosen. Utilizing the help of the STATISTICA software, the results obtained are presented in Tables 2 and 3.

Table 2. Model of Piecewise Linear Regression between $P_{\mathrm{c}}$ and $Z$-Rosenbrock Pattern Search.

\begin{tabular}{|c|c|c|c|c|c|}
\hline \multirow[t]{2}{*}{$n=2570$} & \multicolumn{5}{|c|}{$\begin{array}{l}\text { Model is: Piecewise linear regression with breakpoint } \\
\text { Rosenbrock Pattern Search estimation method } \\
\text { Dependent variable: Pc Loss: Least squares } \\
\text { Final loss: } 230310895 \text { E10R: } 0.77966 \\
\text { Variance explained: } 60.78 \%\end{array}$} \\
\hline & Const. $B_{0}$ & $Z$ & Const. $B_{0}$ & $Z$ & Breakpt. \\
\hline Estimate & $27,612,407$ & 0.044 & $243,864,078$ & -3.077 & $118,583,239$ \\
\hline
\end{tabular}


Table 3. Model of Piecewise Linear Regression between $P_{\mathrm{c}}$ and $Z$-Hooke-Jeeves Pattern Moves.

\begin{tabular}{|c|c|c|c|c|c|}
\hline \multirow[t]{2}{*}{$n=2570$} & \multicolumn{5}{|c|}{$\begin{array}{l}\text { Model is: Piecewise linear regression with breakpoint } \\
\text { Hooke-Jeeves Pattern Moves } \\
\text { Dependent variable: Pc Loss: Least squares } \\
\text { Final loss: } 231885513 E 10 \\
\text { R: } 0.77794 \\
\text { Variance explained: } 60.519 \%\end{array}$} \\
\hline & Const. $B_{0}$ & $Z$ & Const. $B_{0}$ & $Z$ & Breakpt. \\
\hline Estimate & $27,612,407$ & 0.044 & $243,864,078$ & -3.077 & $118,583,239$ \\
\hline
\end{tabular}

In Table 2, the regression coefficients are obtained using the Rosenbrock Pattern Search estimation method with a maximum number of iterations of 200 and a convergence criterion of 0.0001 . Piecewise linear regression with a breakpoint of $118,583,239$ can explain well the pattern of relationships between $Z$ and $P_{c}$ variables, which means that the hypothesis is proven. The equation has a parameter $\mathrm{R}$-square $=60.78 \%$. Similar results were obtained through the Hooke-Jeeves Pattern Moves estimation method, as can be seen in Table 3. According to Rosenbrock Pattern Search estimation method, the following equations were obtained:

$$
\begin{gathered}
P_{c}=27612404+0.044 Z \text { for } Z<118583239 \\
P_{c}=243864978-3.077 Z \text { for } Z>118583239
\end{gathered}
$$

The R-square means that there is a $40 \%$ variation in $P_{c}$ that cannot be explained by changes in $Z$. This number is not too good, but this correlation number is too worthy to discard; this $40 \%$ R-square is used as a chaotic area and is determined as an unwed condition. In this area, high uncertainty occurs where the city's authorities cannot predict changes in Pc based on changes in the $\mathrm{Z}$ as the resilience variable. The boundaries of the unwanted area are determined by looking at the chaotic boundary area with $\left(U_{\mathrm{Z}}, P_{\mathrm{c}}\left(U_{\mathrm{Z}}\right)\right)$ coordinates, or, in other words, the chaotic boundary is limited by ordinate $P_{\mathrm{C}}<P_{\mathrm{c}}\left(U_{\mathrm{Z}}\right)$ and abscissa $Z<U_{Z}$. The chaotic area is located in the value of $U_{Z}$ less than IDR 5,097,592 and $P_{\mathrm{C}}<P_{\mathrm{C}}\left(U_{\mathrm{Z}}\right)=27,816,310.68$, and thus the coordinates of the chaotic boundary area are $(5,097,592: 27,816,310.68)$.

Based on this chaotic boundary area, policymakers can identify which cities have economic resilience and which cities do not. Table 4 provides information on some of the results of the identification of cities in Indonesia that fall into the category of not having economic resilience. Lebak Regency, for example, is classified as not having had economic resilience in the year 2017. To explain the unwanted condition in Lebak Regency, the Human Development Index (HDI) was used. The HDI is a summary measure for assessing long-term progress in three basic dimensions of human development: a long and healthy life, access to knowledge and a decent standard of living. Standard of living in HDI is measured by Gross National Income (GNI) per capita and GRDP at the city or regency level. Therefore, it is very much in line with the concern variable studied in this paper, namely Income per capita. Based on Equation (8), there is a positive linear relationship between modifier variable $Z$ and Concern Variable Pc, Income per capita. So, if Z enters the unwanted condition, $\mathrm{P}_{\mathrm{C}}$ will experience the same thing. The achievement of human development in regencies and cities in 2017 looks quite varied, with the lowest Human Development Index (HDI) for Lebak Regency (62.95) [54], and, until the year 2020, the HDI of Lebak Regency, together with Pandeglang Regency, is still at the lowest position [55]. This condition is in line with the GRDP achieved by Lebak and Pandeglang, which are also at the lowest level. Lebak regency is compared with South Tangerang Municipality, which has an HDI rank of 81.17 and occupies the highest position in the province of Banten, where Lebak and South Tangerang are located. From 2018 to 2020, Banten Province continues to occupy the highest unemployment rate in Indonesia, and South Tangerang had the lowest rate of unemployment, of 8.48 percent. In this study, South Tangerang has a modifier variable, $Z$, which is outside the unwanted condition, meaning that this 
Municipality has economic resilience. C-20 (club twenty) comprises the 20 most prosperous cities or regencies in Indonesia. Lebak and Pandeglang were not in the C-20 until year 2018. The residents of Lebak and Pandeglang prefer to migrate to cities which in this study are outside the unwanted condition.

Table 4. A portion of the city in Indonesia fell into unwanted conditions.

\begin{tabular}{ccccc}
\hline No. & Province & Cities/Regencies & Period & Z \\
\hline 1 & Banten & Pandeglang Regency & 2015 & $1,237,819.52$ \\
\hline 2 & Banten & Pandeglang Regency & 2016 & $1,317,483.28$ \\
\hline 3 & Banten & Pandeglang Regency & 2017 & $1,719,187.30$ \\
\hline 4 & Banten & Pandeglang Regency & 2018 & $2,006,796.57$ \\
\hline 5 & Banten & Pandeglang Regency & 2019 & $1,737,529.14$ \\
\hline 6 & Banten & Lebak Regency & 2015 & $2,110,403.64$ \\
\hline 7 & Banten & Lebak Regency & 2016 & $2,086,929.41$ \\
\hline 8 & Banten & Lebak Regency & 2017 & $2,878,942.67$ \\
\hline
\end{tabular}

These facts show that the unwanted condition as a criterion for determining the economic resilience status of a regency/city is promising. In Southeast Asia, the rate of distribution of Indonesia's population in urban areas is the second highest, at $54.7 \%$. This statistic points out that living in big cities has increased enormously, and half of the total Indonesian population live in urban areas. Banten is one of the five provinces with the largest urbanization rate in Indonesia with an urbanization rate above 65 percent [56]. These are the impacts of Indonesia's economy, which is still very centralized in Java, which covers nearly 60 percent of the total GDP. The results of the economic resilience status analysis of a city are very useful for policymakers to determine the strategic direction of development. Development program diversification is a logical consequence based on the city's economic resilience status. There are quality improvement programs for cities that do not have resilience and retention programs for cities that already have resilience.

\section{Conclusions, Limitations and Recommendation}

\subsection{Conclusions}

Based on the results of the statistical analysis of the relationship between two groups of variables $-Z$ as the modifier variable ( $Z$ is the ratio between the original incomes of the region and the number of poor people in a city) and $P_{\mathrm{c}}$ as the concern variable (the ratio between gross regional domestic product and population) —on all 514 cities in Indonesia in a five-year observation period, from the year 2015 to the year 2019, the following conclusions are presented:

1. Based on the results of the Chaotic area method in all cities in Indonesia, there are $30 \%$ cities that lack economic resilience. In Banten Province, Pandeglang Regency was had no economic resilience for 5 consecutive years (2015-2019), while Lebak Regency was in the same situation from 2015 to 2017. This result is confirmed by the fact that Banten Province had the highest unemployment rate in Indonesia from 2018 to 2020. Banten is one of the five provinces with the largest urbanization rate in Indonesia, with an urbanization rate above 65 percent. Until 2020 the HDI of Lebak Regency, together with Pandeglang, was still at the lowest position. On the other hand, South Tangerang, which is classified as having economic resilience by the Chaotic method, is in fact one of the 20 most prosperous cities in Indonesia, with the lowest rate of unemployment, of 8.48 percent. The rates of urbanization in Lebak Regency and Pandeglang are above 65 percent, which indicates that the residents of Lebak and Pandeglang prefer to migrate to cities having a modified variable, $Z$, outside the unwanted condition. 
2. The chaotic area method developed in this paper is effective in assessing the economic resilience on the City/Regency level. This method is developed to overcome the shortcomings of the index method commonly used internationally, as reported by Bandura [5]. The index cannot identify specifically the level of disturbance intensity that will plunge a city into economic non-resilience. An FVU area is a condition of uncertainty and unpredictability, so that people will avoid this area. This condition is chaotic and declared as an unwanted condition. No authority is willing to be in a condition of high uncertainty. Thus, cities that enter this uncertainty area are classified as cities that are in unwanted conditions. A city with a low Z, such as Pandeglang and Lebak, indicates the position of the city in life-saving mode. On the other hand, cities that have high $\mathrm{Z}$, such as South Tangerang, are in a growing mode, because the PAD is not burdened by the cost center, making it possible to invest in various productive development programs.

3. The novelty of this research is the firmness in determining the economic resilience status of a city. Based on the literature review, if it is not reflected by an index, then economic resilience is described in a disturbance model and no literature was found that explicitly defines unwanted conditions. Only if economic resilience variable $\mathrm{Z}$ falls into a chaotic area as unwanted conditions is a city claimed as not resilient economically. The results of the economic resilience status classification of a city are very useful for policymakers to determine the strategic direction of the development. Based on the output of this research, the development priority program for each city becomes distinctive depending on the status of the city's economic resilience. There are quality improvement programs for cities that do not have resilience and retention programs for cities that already have economic resilience.

\subsection{Limitations and Recommendation}

This study limits economic resilience to the level of the city, and not the provincial or even country level. Furthermore, this study does not discuss the model of economic disturbances in determining the economic resilience status of a city. Disturbance models and unwanted condition models are both important and must be present as determinants in establishing the economic resilience status of a city. This study cannot stand alone. The unwanted condition as a criterion in determining economic resilience at the city level is a stepping stone for developing a measurement model for city economic resilience that integrates both disturbance and unwanted condition models. Therefore, research that integrates the disturbance model and unwanted condition simultaneously is the next research plan. The economic resilience status of a city cannot be determined by just having an unwanted condition model or a disturbance model. Both models must be present.

This study recommends determining the economic resilience status of a city based on an assessment of the modifier variable, $Z$, as a substitute for the index approach. If $Z$ is in the unwanted condition, the income per capita will also deteriorate and the city is declared to have no economic resilience.

Author Contributions: Conceptualization, Y.H. and T.P.; methodology, Y.H. and T.P.; software, S. (Subiyanto); validation, S. (Sukono) and S. (Subiyanto); formal analysis, Y.H. and T.P.; investigation, Y.H. and T.P.; data curation, S. (Sukono) and S. (Subiyanto); writing-original draft preparation, Y.H. and S. (Subiyanto); writing-review and editing, Y.H. and S. (Subiyanto); visualization, S. (Subiyanto); supervision, S. (Sukono); project administration, S. (Subiyanto); funding acquisition, Y.H. All authors have read and agreed to the published version of the manuscript.

Funding: The Lecturers Competence Research Grant of Universitas Padjadjaran (RKDU), with a contract number: 1427/UN6.3.1/LT/2020.

Institutional Review Board Statement: Not applicable.

Informed Consent Statement: Not applicable. 
Acknowledgments: The authors are grateful to the constructive comments from three anonymous reviewers. The author would also like to thank the Dean of the Faculty of Mathematics and Natural Sciences, Universitas Padjadjaran, and the Directorate of Research and Community Service (DRPM). Any attempt at any level could not have been satisfactorily completed without the support and guidance of my wife and friends. I would like to express my special gratitude to my best friend Ronny Djuliawan, who helped me in this research and through whom I came to know many new things. I am very thankful to him.

Conflicts of Interest: The authors declare no conflict of interest.

\section{References}

1. Government Work Plan for 2021; Minister of National Development Planning: Jakarta, Indonesia, 2020; pp. 1-185.

2. The World Bank. The World Bank in Indonesia. 2020. Available online: https://www.worldbank.org/en/country/indonesia/ overview\#1 (accessed on 1 October 2020).

3. Ramda, E.E. Strengthening of national resilience: Leading sector mapping for digital economy in indonesia. Adv. Econ. Bus. Manag. Res. 2020, 151, 41-46. [CrossRef]

4. Kusumastuti, R.D.; Viverita; Husodo, Z.A.; Suardi, L.; Danarsari, D.N. Developing a resilience index towards natural disasters in Indonesia. Int. J. Disaster Risk Reduct. 2014, 10, 327-340. [CrossRef]

5. Bandura, R.; Del Campo, M. Survey of Composite Indices Measuring Country Performance: 2006 Update. Available online: http:/ / www.eldis.org/vfile/upload/1/document/1112/measuring_country_performance_2006update.pdf (accessed on 8 March 2021).

6. Yu, K.D.S.; Aviso, K.B.; Santos, J.R.; Tan, R.R. The economic impact of lockdowns: A persistent inoperability input-output approach. Economies 2020, 8, 109. [CrossRef]

7. Modica, M.; Reggiani, A. Spatial economic resilience: Overview and perspectives. Netw. Spat. Econ. 2015, 15, 211-233. [CrossRef]

8. Martin, R.; Sunley, P.; Gardiner, B.; Tyler, P. How regions react to recessions: Resilience and the role of economic structure. Reg. Stud. 2016, 50, 561-585. [CrossRef]

9. Martin, R. Regional economic resilience, hysteresis and recessionary shocks. J. Econ. Geogr. 2011, 12, 1-32. [CrossRef]

10. Rose, A.; Krausmann, E. An economic framework for the development of a resilience index for business recovery. Int. J. Disaster Risk Reduct. 2013, 5, 73-83. [CrossRef]

11. Hill, E.W.; Wial, H.; Wolman, H. Exploring Regional Economic Resilience. 2008. Available online: http://www.econstor.eu/ handle/10419/59420 (accessed on 8 March 2021).

12. Foster, K.A. A Case Study Approach to Understanding Regional Resilience. 2007. Available online: https:/ / escholarship.org/uc/ item/8tt02163 (accessed on 8 March 2021).

13. Bastaminia, A.; Rezaei, M.R.; Saraei, M.H. Evaluating the components of social and economic resilience: After two large earthquake disasters Rudbar 1990 and Bam 2003. Jàmbá J. Disaster Risk Stud. 2017, 9, 12. [CrossRef] [PubMed]

14. Bakhtiari, S.; Sajjadieh, F. Theoretical and empirical analysis of economic resilience index. Iran. J. Econ. Stud. J. 2018, 7, 41-53. [CrossRef]

15. Vale, L.J.; Campanella, T.J. The Resilient City: How Modern Cities Recover from Disaster; Oxford University Press: Oxford, UK, 2005.

16. Hallegatte, S. Economic resilience: Definition and measurement. World Bank Policy Res. Work. Pap. 2014, 6852, 1-44. [CrossRef]

17. Walker, B.; Carpenter, S.R.; Anderies, J.M.; Abel, N.; Cumming, G.; Janssen, M.A.; Lebel, L.; Norberg, J.; Peterson, G.D.; Pritchard, R. Resilience management in social-ecological systems: A working hypothesis for a participatory approach. Conserv. Ecol. 2002, 6, 14. [CrossRef]

18. Martin, R.; Sunley, P. Complexity thinking and evolutionary economic geography. J. Econ. Geogr. 2007, 7, 573-601. [CrossRef]

19. Pike, A.; Dawley, S.; Tomaney, J. Resilience, adaptation and adaptability. Camb. J. Reg. Econ. Soc. 2010, 3, 59-70. [CrossRef]

20. Pendall, R.; Foster, K.A.; Cowell, M. Resilience and regions: Building understanding of the metaphor. Camb. J. Reg. Econ. Soc. 2009, 3, 71-84. [CrossRef]

21. Miyasto. Sistem Pengukuran Ketahanan Nasional Dan Simulasi Kebijakan Publik—Pedoman Pengukuran; Laboratorium Pengukuran Ketahanan Nasional: Jakarta, Indonesia, 2015.

22. Sukoyo, Y. Pandemi Covid-19 Turunkan Indeks Ketahanan Nasional. 2020. Available online: https://www.beritasatu.com/nasional/ 702977 / pandemi-covid19-turunkan-indeks-ketahan-an-nasional\#: \{\}:text=\%22DarihasilpengukuranLaboratoriumKetahanan, artinyaketahanannasionalcukuptangguh.\&text=Padaawaltahunketahananekonomi,2\%2C65padaJuni2020 (accessed on 27 April 2021).

23. Bruneckiene, J.; Palekienè, O.; Simanavičienè, Ž.; Rapsikevičius, J. Measuring regional resilience to economic shocks by index. Eng. Econ. 2018, 29, 405-418. [CrossRef]

24. Li, L.; Zhang, P.; Li, X. Regional economic resilience of the old industrial bases in China-A case study of Liaoning Province. Sustainability 2019, 11, 723. [CrossRef]

25. Stanickova, M.; Melecký, L. Understanding of resilience in the context of regional development using composite index approach: The case of European Union NUTS-2 regions. Reg. Stud. Reg. Sci. 2018, 5, 231-254. [CrossRef]

26. Di Caro, P. Testing and explaining economic resilience with an application to Italian regions. Pap. Reg. Sci. 2015, 96, 93-113. [CrossRef] 
27. Oprea, F.; Onofrei, M.; Lupu, D.; Vintila, G.; Paraschiv, G. The determinants of economic resilience. The case of Eastern European regions. Sustainability 2020, 12, 4228. [CrossRef]

28. Simmie, J.; Martin, R. The economic resilience of regions: Towards an evolutionary approach. Camb. J. Reg. Econ. Soc. 2010, 3, 27-43. [CrossRef]

29. Oliva, S.; Lazzeretti, L. Measuring the economic resilience of natural disasters: An analysis of major earthquakes in Japan. City Cult. Soc. 2018, 15, 53-59. [CrossRef]

30. Lorenz, E.N. Deterministic nonperiodic flow. J. Atmos. Sci. 1963, 20, 130-141. [CrossRef]

31. Briguglio, L.; Cordina, G.; Farrugia, N.; Vella, S. Economic vulnerability and resilience: Concepts and measurements. Oxf. Dev. Stud. 2009, 37, 229-247. [CrossRef]

32. Central Bureau of Statistics. Study Economic Resilience For 514 Cities In Indonesia From Year 2015-2019. Available online: https: / / www.bps.go.id (accessed on 8 March 2021).

33. Hidayat, Y.; Purwandari, T.; Sukono, S.; Supian, S.; Juahir, H.; Kamarudin, M.K.; Yusra, A.I. Improving unprecedented restlessness as the new strong the new strong indicator of rice crisis at national level. J. Fundam. Appl. Sci. 2018, 10, 128-138. [CrossRef]

34. Central Bureau of Statistics. Gross Regional Domestic Product of Provinces in Indonesia by Industry 2013-2017; Central Bureau of Statistics: Jakarta, Indonesia, 2018.

35. Gkioulekas, I.; Papageorgiou, L.G. Piecewise regression analysis through information criteria using mathematical programming. Expert Syst. Appl. 2019, 121, 362-372. [CrossRef]

36. Malash, G.F.; El-Khaiary, M.I. Piecewise linear regression: A statistical method for the analysis of experimental adsorption data by the intraparticle-diffusion models. Chem. Eng. J. 2010, 163, 256-263. [CrossRef]

37. Ritzema, H. Drainage Principles and Applications; International Institute for Land Reclamation and Improvement (ILRI): Wageningen, The Netherlands, 1996.

38. Haines, C.F. Implicit integration processes with error estimate for the numerical solution of differential equations. Comput. J. 1969, 12, 183-187. [CrossRef]

39. Cash, J.R. Semi-Implicit Runge-Kutta procedures with error estimates for the numerical integration of stiff systems of ordinary differential equations. J. Assoc. Comput. Mach. 1976, 23, 455-460. [CrossRef]

40. Bui, T. On an L-stable method for stiff differential equations. Inf. Process. Lett. 1977, 6, 158-161. [CrossRef]

41. Dodangeh, M.; Vicente, L.N.; Zhang, Z. On the optimal order of worst case complexity of direct search. Optim. Lett. 2016, 10, 699-708. [CrossRef]

42. Taib, H.; Bahreininejad, A. Data clustering using hybrid water cycle algorithm and a local pattern search method. Adv. Eng. Softw. 2021, 153, 102961. [CrossRef]

43. Aras, S.; Gedikli, E.; Kahraman, H.T. A novel stochastic fractal search algorithm with fitness-distance balance for global numerical optimization. Swarm Evol. Comput. 2021, 61, 100821. [CrossRef]

44. Peng, H.; Zeng, Z.; Deng, C.; Wu, Z. Multi-strategy serial cuckoo search algorithm for global optimization. Knowl. Based Syst. 2021, 214, 106729. [CrossRef]

45. Brosse, N.; Durmus, A.; Moulines, É.; Sabanis, S. The tamed unadjusted Langevin algorithm. Stoch. Process. Appl. 2019, 129, 3638-3663. [CrossRef]

46. Altinoz, O.T.; Yilmaz, A.E. Multiobjective Hooke-Jeeves algorithm with a stochastic Newton-Raphson-like step-size method. Expert Syst. Appl. 2019, 117, 166-175. [CrossRef]

47. Sambas, A.; Sukono; Zhang, S.; Vaidyanathan, S.; Hidayat, Y. Mujiarto electronic circuit design of a novel chaotic system with apple-shaped curve equilibrium and multiple coexisting attractors. J. Phys. Conf. Ser. 2020, 1477, 22015. [CrossRef]

48. Safonov, L.A.; Tomer, E.; Strygin, V.V.; Ashkenazy, Y.; Havlin, S. Multifractal chaotic attractors in a system of delay-differential equations modeling road traffic. Chaos Interdiscip. J. Nonlinear Sci. 2002, 12, 1006-1014. [CrossRef]

49. Sahni, R. Analysis of stock market behaviour by applying chaos theory. In Proceedings of the 9th International Conference on Computing, Communication and Networking Technologies (ICCCNT), Bengaluru, India, 10-12 July 2018; pp. 1-4.

50. Jingbo, W.; Zhigang, Y.; Jingtao, W. Chaos in traffic flow based on LA model. In Proceedings of the Communications in Computer and Information Science (ICICA), Singapore, 16-18 August 2013; pp. 120-129.

51. Draper, N.R.; Smith, H. Applied Regression Analysis, 3rd ed.; Wiley-Interscience: Hoboken, NJ, USA, 1998.

52. Glantz, S.A.; Slinker, B.K.; Neilands, T.B. Primer of Applied Regression and Analysis of Variance, 3rd ed.; McGraw-Hill Education: New York, NY, USA, 2016.

53. Steel, R.G.D.; Torrie, J.H. Principles and Procedures of Statistics with Special Reference to the Biological Sciences; McGraw-Hill Education: London, UK, 1960.

54. Soebeno, A. Human Development Index, Banten, 2016-2017; United Nations Development Programme (UNDP): New York, NY, USA, 2017.

55. Wiriana, A. Human Development Index, Banten, 2019-2020; United Nations Development Programme (UNDP): New York, NY, USA, 2020.

56. Rahayu, T.E. Population Growth and Distribution of Indonesia; Central Bureau of Statistics: Jakarta, Indonesia, 2011. 